\title{
Simulation and measurement of microclimate in roof space on a gothic truss construction
}

\author{
Radoslav Ponechal $^{1,{ }^{*}}$, Peter Krušinský ${ }^{1}$, Peter Pisca ${ }^{1}$, and Renáta Korenková ${ }^{2}$ \\ ${ }^{1}$ University of Zilina, Faculty of Civil Engineering, Univerzitna 8215/1, 01026 Žilina, Slovakia \\ ${ }^{2}$ Babkov 63, 013011 Lietavská Svinná - Babkov, Slovakia
}

\begin{abstract}
Research in the field of historical trusses has long been performed at the workplace of the authors. In each truss, there was recorded the general technical state and some even monitoring and analysing microclimate with the aim of specifying environmental conditions that would be suitable for preservation of a historical structure. The article shows the results of temperature and relative humidity measurement in roof space of the Roman-Catholic church in the historical centre of the village of Bela-Dulice as well as result of thermodynamic simulation of this space. The selected measurement was compared to the simulation results.
\end{abstract}

\section{Introduction}

If we want to maintain a good technical condition of the timber structures of the truss it is necessary to ensure microclimate conditions in a roof space. Boundary conditions can be the way of ventilating, external environment (outdoor air temperature, relative air humidity, wind, rain, altitude, location) and internal environment (temperature, relative air humidity, air circulation). The impact of boundary conditions on wood humidity is addressed by other articles [1]. The long-lasting influence of unfavourable conditions has a negative effect on physical and mechanical characteristics of timber components, and it consequently leads to degradation or other unwanted changes in statics of a building. It is known that absolute moisture that is critical for occurring biotic forms of damage is as follows: around $10 \%$ for ligniperdous insects, more than $20 \%$ for dry rot, depending on the length of exposure [2].

The air flow and temperature distributions in a roof space are affected by the temperature difference between the ambient and a roof space, the solar radiation absorbed by the roof, the thermal accumulation mass of the ceiling and the mass air flow which inters through inlet vents. Long-term measurements of the indoor environment help to understand this system. But a more detailed picture provides simulations [3]. This dynamic phenomenon is well described in the study Comsol simulation software [4]. They show that solar radiation increases the hourly attic air circulation during buoyancy driven ventilation. They prove also that higher attic insulation thickness decreases attic ventilation rate during the winter period. Measurements have usually certain limitations in the number of monitoring

\footnotetext{
* Corresponding author: radoslav.ponechal@,fstav.uniza.sk
} 
points and observed quantities. Also by using the tested simulation model, alternative interventions can be explored. Both methods are used here for a more complete analysis.

\section{Building and model description.}

This article is evaluated the Roman-Catholic church of the Most Holy Body of Christ in the historical centre of the village of Bela-Dulice (see Fig. 1). It probably arose in the first half of the 14th century. It has two separated truss structures, over the nave and the sanctuary. The truss over the nave was a subject of our investigation [5]. The steep truss over the nave has a rafter construction with collar beams, it is longitudinally bound with a central framed trestle.

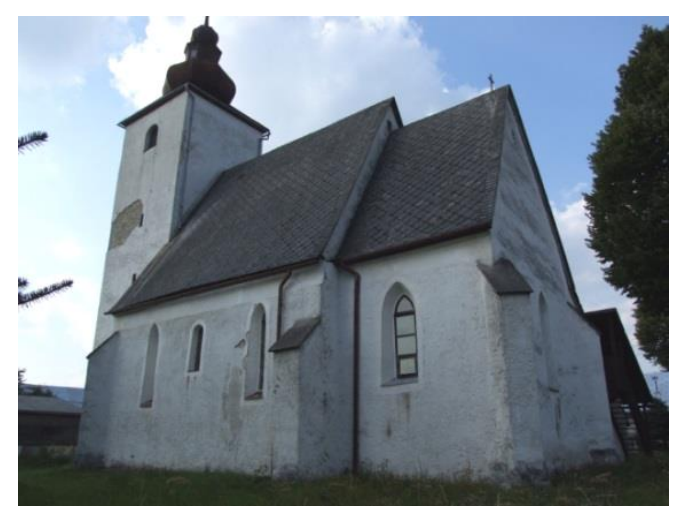

Fig. 1. Picture of Roman-Catholic church in Bela-Dulice.

\subsection{Simulation model}

The simulation model of the church consists of 12 zones. One zone represents the temple, three zones represent tower, three zones sanctuary and five zones the main roof space.

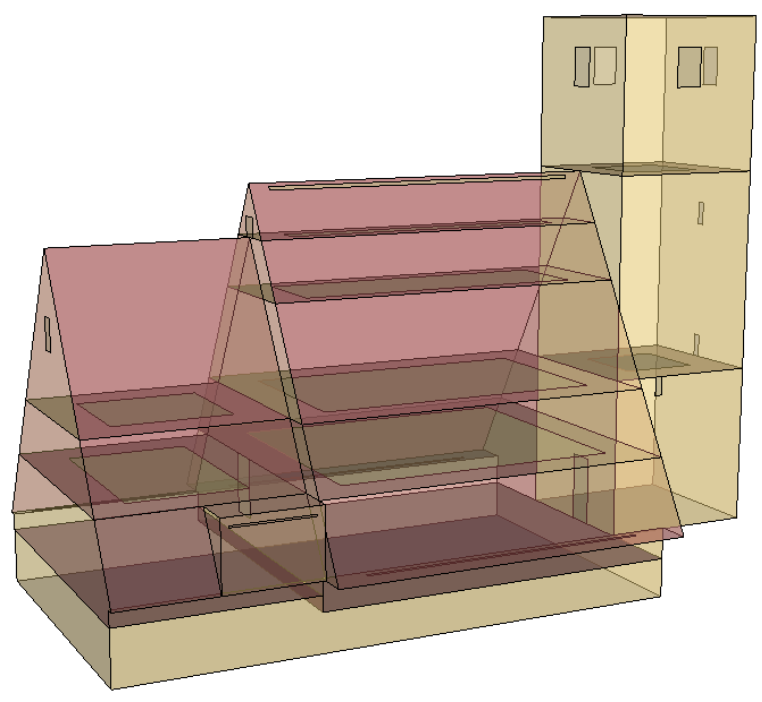

Fig. 2. The view of the simulation model. 
The Energy-Plus simulation program counts a significant thermal accumulation in tower's walls made of the stone. The program also calculates the thermal radiation from roofing and increases the air temperature. Temperature in the temple zone is constantly 18 ${ }^{\circ} \mathrm{C}$. Fictive surfaces are used to join individual zones, which are connected by air. Some wood of the truss is embedded as furniture and contributes to accumulation. The openings are not glazed.

\subsection{Air flow model}

To make an airflow simulation in such a place, it is necessary to take account of all openings through which the air exchange between a roof space and the exterior could happen. The buoyancy driven natural ventilation air flow model is used. The most airflow components are embedded as effective leakage area, with discharge coefficient from 0.5 to 0.65 . Through this component it allows the air to flow in one direction only.

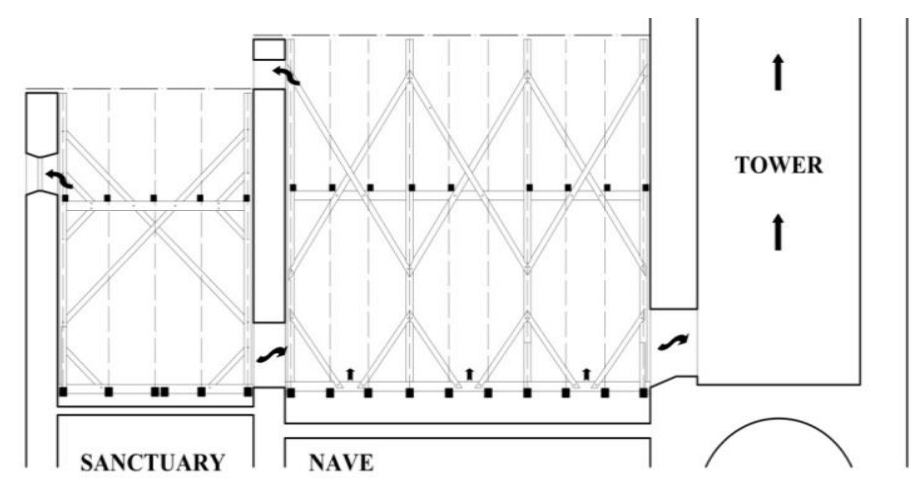

Fig. 3. The main air flow paths in roof and tower.

\section{Experimental measurements}

\subsection{The measuring system}

The examined pitched roof has a slope of 59 $64^{\prime}$ [5] with gable walls. The roof deck comprises sheet copper roofing used in strips; the joints of particular strips have standing seams. As the roof space is open towards the outside - it has openings as in the lower so in the upper part of the roof deck, in the top of the gable wall, passage openings in the tower gable wall and in the truss gable wall over the sanctuary - the roof can be considered as a ventilated double-cladding pitched roof.

To enter reliable and real data into the airflow simulation, and to detect an actual as well as a long-term impact of microclimate in a roof space on the moisture accumulation in timber elements, the measuring system with two types of sensors for a particular space was designed. Particular temperature and relative air humidity sensors, and also sensors for scanning the temperature and absolute moisture of timber elements are found on spots where there is a precondition of airflow. Their disposition is symmetrical in relation to the roof ridge, i.e. they are disposed evenly on the western and southern side in the roof space.

Some sensors are located in the lowest roof part, exactly in the exterior under the gutter cornice (sensor 01 and 02). Additional sensors have their positions in the exterior near the opening in the eastern gable wall, in openings in gable walls leading into trusses over the 
sanctuary (06) and into the tower (07). Other sensors are found in the roof space - in the middle of the object under the roof ridge (08), and in the midpoint of the roof plane length (03 and 04) - see the scheme in Fig. 4.Captions should be typed in 9-point Times. They should be centred above the tables and flush left beneath the figures.

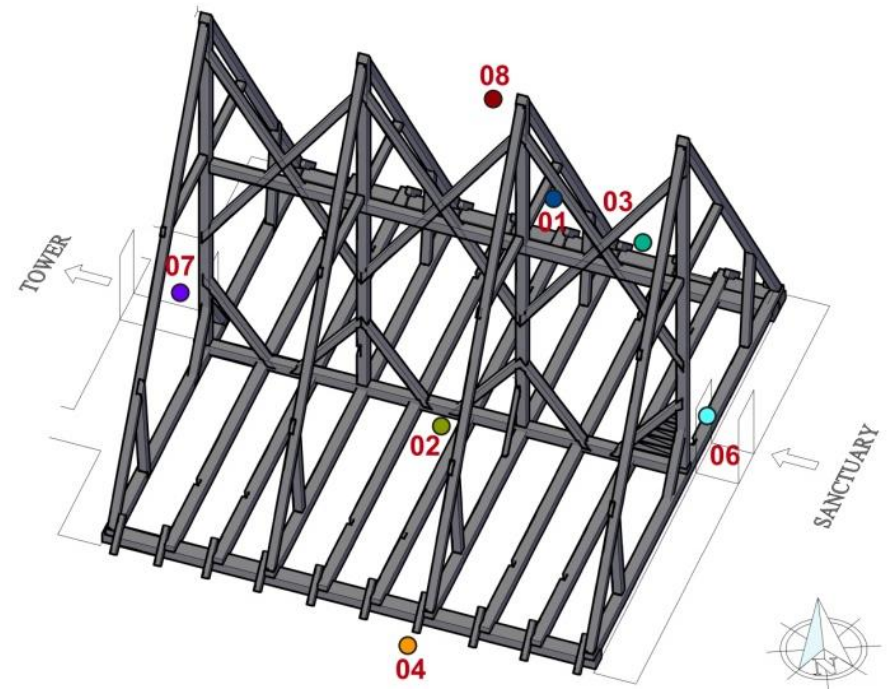

Fig. 4. The dispositional scheme of sensors V1 used as a measuring system.

\subsection{Microclimate in the roof space}

Temperatures and relative air humidity are monitored with sensors at 15 -minutes intervals. For calculations, data gathered at 7:00, 14:00 and 21:00 o'clock within summer time was considered - Fig.5. Average day temperatures and relative air humidity are calculated using obtained data - Fig. 6, Fig. 8. All evaluated data from sensors, as in spring so in autumn season, reached temperature maximums at 14:00 o'clock - Table 1. Most sensors recorded temperature minimums at 7:00 o'clock; and all sensors in autumn season. As to complete evaluation, sensor No. 8 (located closely to the roof ridge) recorded the highest temperatures at 7:00, 14:00 and also at 21:00 o'clock. Relative air humidity goes to minimum in these spots. The roof ridge has no ventilation, thus there isn't any obvious airflow. There is sheet copper roofing used in strips on wooden slabs. The sensor No.07, found in the gable wall opening running into the tower, registered temperature minimums at 14:00 o'clock. At the same time, temperatures that were monitored with this sensor showed the smallest differences.

The tower has a square ground plan. It is made of stone and its walls are $800 \mathrm{~mm}$ thick. During daytime, there isn't any air overheating, and for the wall has high ability of accumulation, there isn't either any significant air cooling. And that's why there is no markedly cool air in early morning, in contrast to the truss space. 


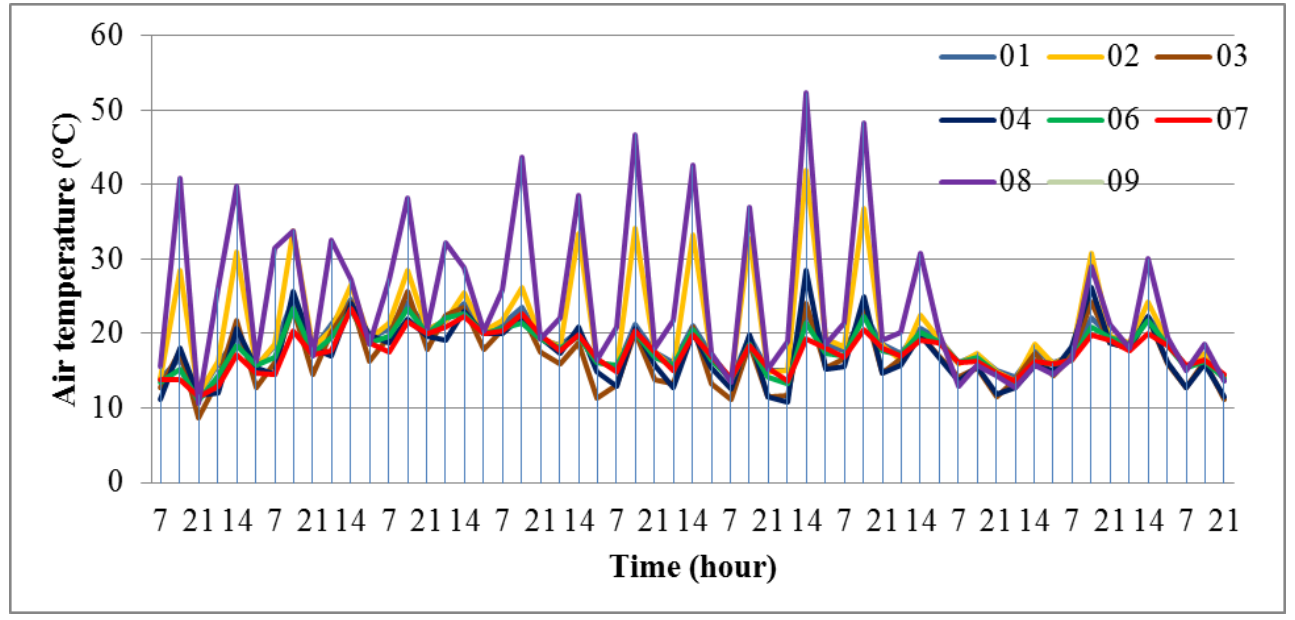

Fig. 5. The course of air temperatures recorded at 7:00, 14:00 and 21:00 o'clock - spring season 2012 (18.5.2012-5.6.2012).

In most cases, temperature minimum was recorded with sensor No. 04, position of which is in the exterior on the northern side of a building, and with sensor No. 03 located near eaves in the exterior on the northern side of the building. Lowest temperatures in both seasons were found out using the outdoor sensor on the northern side of a building under the gutter cornice. Sensors No. 08 (under the roof ridge) and No. 02 (under roofing on the southern side of building) monitored considerable temperature fluctuations. It is these spots in the truss that air overheating occurs, which is caused by the effect of sunrays during the day.

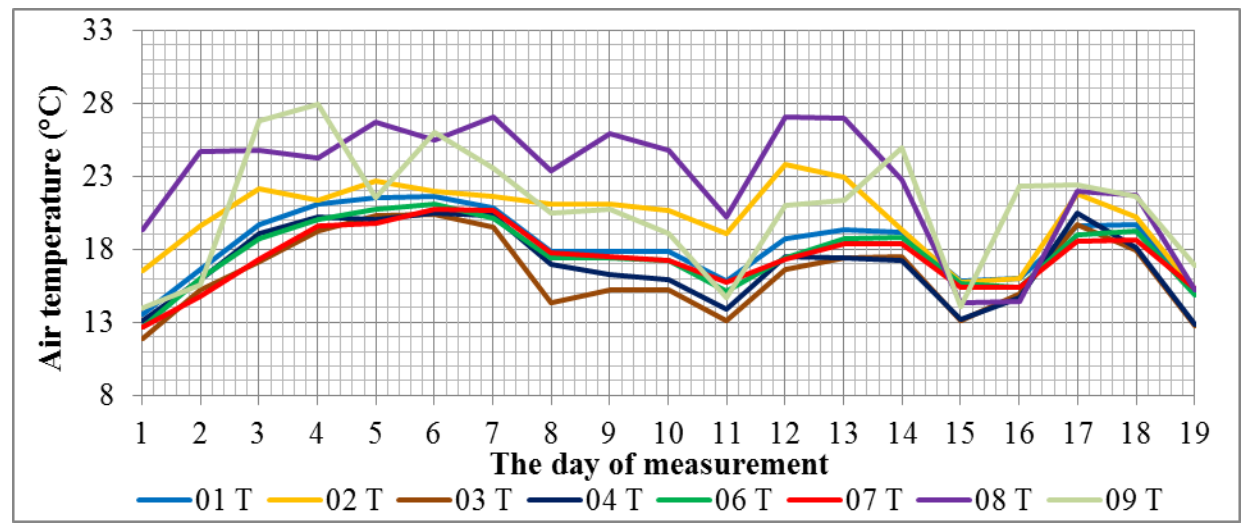

Fig. 6. Average day air temperatures recorded at 7:00, 14:00 and 21:00 o'clock - spring season 2012 $(18.5 .2012-5.6 .2012)$.

\section{Microclimate and ventilating numerical simulation}

The simulation results can be compared with the measurement. But achieved results can not match in short time records. This is because the simulation calculates the average temperature in the zone while the temperature is measured at a specific location. Also Ostrava IWEC test reference year was used instead of current climate data. 


\subsection{Microclimate simulation results}

From the results in the hourly time step, the daily average temperature was made. The average daily temperature in this season period is around $20{ }^{\circ} \mathrm{C}$ in cloudy day and from 21 to $24{ }^{\circ} \mathrm{C}$ in sunny day. This is similar to the measurement result. The temperature difference between the height in sunny day is $4 \mathrm{~K}$. This is less than measured, but the following aspect should be considered: the measured values are differentiated not only by height but also by location on the sunny side (T 01 and T02). The simulation model is designed as no accounting the location on the sunny side. The solar heat gain by simulation is transferred to the whole zone uniformly.

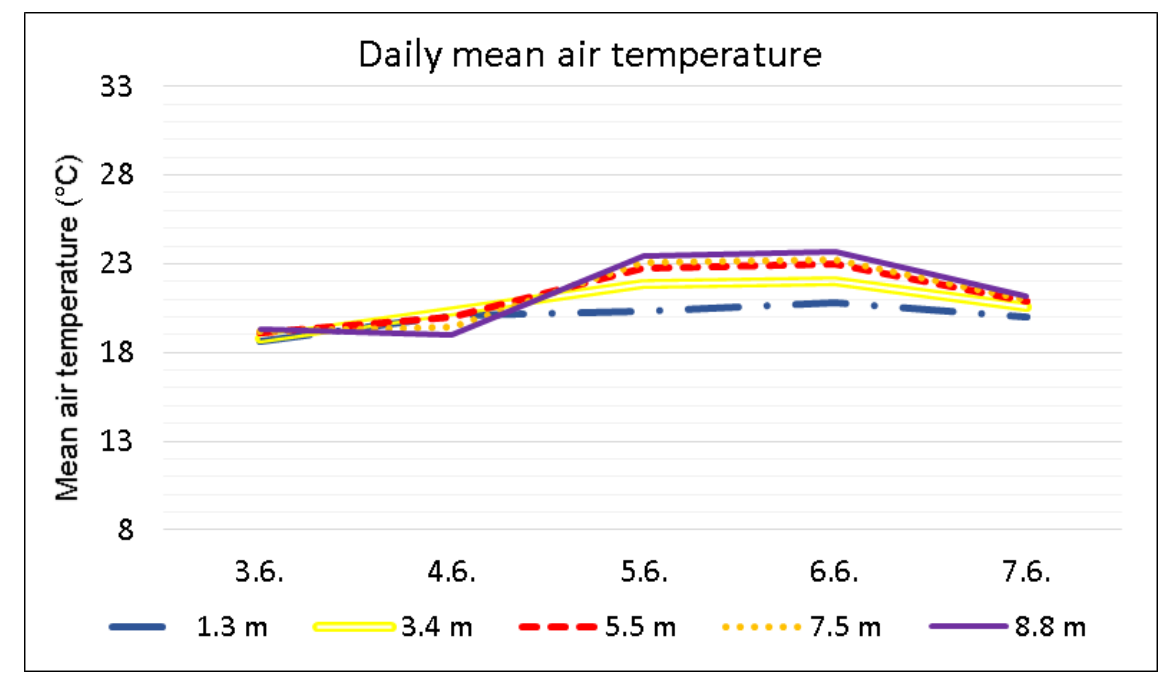

Fig. 7. Daily average air temperatures in roof space from simulation in different height from bottom with Ostrava IWEC test reference year.

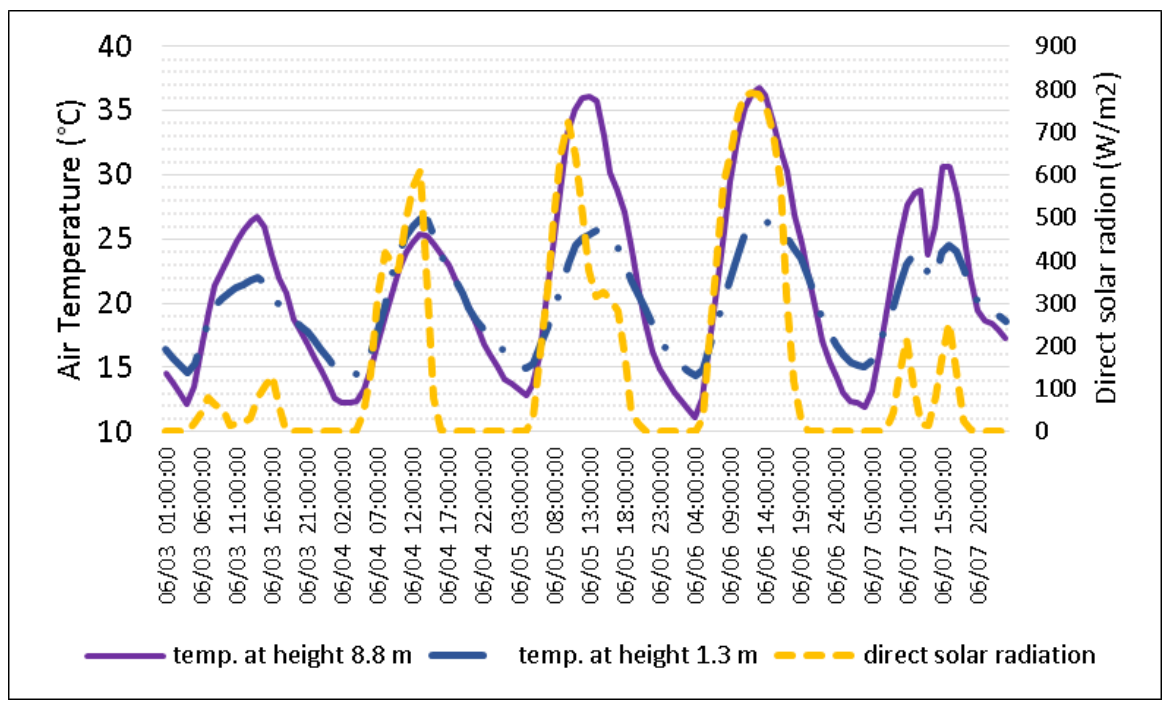

Fig. 8. Hourly simulation results. 
Figure 8 shows the hourly simulation results. With higher direct solar radiation, the temperature in the roof rises especially in the upper part. But Air temperature in the roof is also affected by wind (see Fig. 9). Wind affects the ventilation of the roof. It cools the roof space on warm days. The image of the air flow shows that air flows through the day from the bottom up and at night from the top down. At a time of stronger wind it may be different. There is air movement in the roof space at any time by simulation.

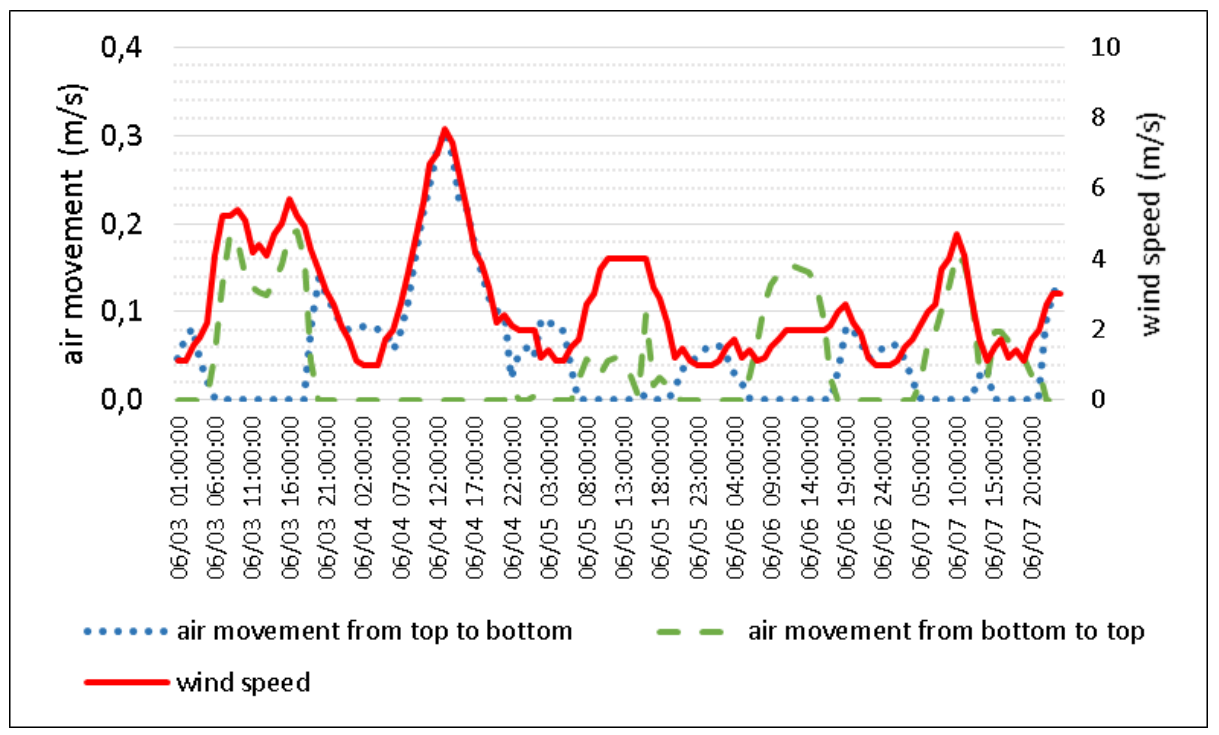

Fig. 9. Hourly simulation results of vertical air movement in roof space.

\section{Conclusions}

Temperatures and relative air humidity in roof space of the Roman-Catholic church of the Most Holy Body of Christ in the historical centre of the village of Bela-Dulice are monitored in spring, summer and autumn season. The spring measurement was compared to the simulation results. The temperature difference between the height in sunny day was less than measured because the simulation model is designed as no accounting the location on the sunny side. There is permanently vertical air movement in the roof space at any time by simulation. The air flow simulation model expects that the air flows through the day from the bottom up and at night from the top down. The tower structure that is connected with the roof space contributes to this. To look at it in more detail would be interesting in the future.

\section{References}

1. R. Korenkova, Effect of Microclimate Historic Truss under Roof Space on the Timber Construction, Stavebne hmoty Protection, s. 24-27, vol. 9, 1 (2013)

2. L. Reinprecht, Wood Protection (TU, Zvolen, 2008)

3. F. Tariku, E. Iffa, Effect of attic insulation thickness and solar gain in a mild climate, Energy procedia, s. 67-72, 78 (2015) 
4. W. Shimin, S. Zhigang, G. Linxia, Numerical simulation of buoyancy-driven turbulent ventilation in attic space under winter conditions, Energy and Buildings, s. 360-368, 47 (2012)

5. E. Capkova, P. Krusinsky, Geometric Analysis of Gothic Roman Catholic Church Roof in the Village of Bela-Dulice, IX. intern. scientific conference FCE TUKE, May 2225, (2012) 